\title{
O efeito do contexto e posição da pergunta no questionário sobre o resultado da medição
}

\author{
Alberto Carlos Almeida
}

Universidade Federal Fluminense

\section{Resumo}

Este artigo aborda um tema tradicional dos erros de medição, o questionário e, mais especificamente, a posição da pergunta no questionário. Veremos que perguntas idênticas, ou muito semelhantes, podem levar a resultados completamente diferentes dependendo da posição da pergunta no questionário e, adicionalmente, do assunto tratado pelo questionário. O artigo mostra que uma mesma pergunta, sobre a memória do voto em Benedita da Silva, uma política negra do Partido dos Trabalhadores, obteve resultados muito diferentes em pesquisas semelhantes em tudo, excetuando-se os seus respectivos temas e a posição desta pergunta no questionário.

Palavras-chave: Erro de medição, metodologia, construção de questionário, memória do voto

\begin{abstract}
This article focus on a traditional issue of measurement error, the questionaire and, more specifically, the question position. One will see that identical questions, or very similiar ones, can lead to totally different results, depending on the question position on the questionaire and, in addition, on the issue. This article shows that the same question about the voting memory in Benedita da Silva, a black woman, politician of the Worker's Party, has obtained very different results in very similar surveys, except for the position question on their questionnaires.
\end{abstract}

$\underline{\text { Key words: }}$ Error of measurement, methodology, question building, voting memory 
Este artigo aborda um tema tradicional dos erros de medição, o questionário e, mais especificamente, a posição da pergunta no questionário. Será visto que perguntas idênticas, ou muito semelhantes, podem levar a resultados completamente diferentes dependendo da posição da pergunta no questionário e, adicionalmente, do assunto tratado pelo questionário. Veremos que uma mesma pergunta, sobre a memória do voto em Benedita da Silva, obteve resultados muito diferentes em pesquisas semelhantes em tudo, excetuando-se os seus respectivos temas e a posição desta pergunta no questionário. Este artigo é, portanto, um case metodológico, uma ilustração prática de um erro não-amostral, um erro de medição ${ }^{1}$.

\section{Controlando possíveis variáveis explicativas da variação dos resultados}

Para que seja possível afirmar com um mínimo de certeza que perguntas semelhantes ou idênticas, levam a resultados totalmente diferentes dependendo do tema da pesquisa e da posição da pergunta no questionário, é preciso controlar as demais possíveis variáveis explicativas de tal variação. Assim, antes mesmo de apresentar as perguntas e suas formulações cumpre apresentar as principais características técnicas das duas pesquisas que foram utilizadas para este experimento. As duas pesquisas a que me refiro são as pesquisas DataUff-CEAP e DataUff-luperj, e suas principais características técnicas estão na Tabela 1 abaixo. Estas características referem-se ao levantamento de dados realizado no município do Rio de Janeiro².

TABELA 1

Características das duas pesquisas para o Município do Rio de Janeiro

\begin{tabular}{|l|c|c|}
\cline { 2 - 3 } \multicolumn{1}{c|}{} & DataUff-CEAP & DataUff-luperj \\
\hline Tema da pesquisa & Relações raciais & Comportamento político \\
\hline Tamanho da amostra & 418 & 496 \\
\hline Tipo de amostra & Probabilística & Probabilística \\
\hline Técnica de entrevista & Domiciliar & Domiciliar \\
\hline Duração aproximada da entrevista & 1 hora & 1 hora \\
\hline Número de perguntas & 210 & 310 \\
\hline Período de realização & $29 / 01 / 00$ a $12 / 04 / 00$ & $02 / 08 / 00$ a 01/10/00 \\
\hline Período de realização de 95\% das entrevistas & $29 / 01 / 00$ a $11 / 04 / 00$ & $08 / 08 / 00$ a 09/09/00 \\
\hline
\end{tabular}

\footnotetext{
${ }^{1}$ Há uma bibliografia extensa, em língua inglesa, sobre erro não amostral e erros oriundos de formulação de questionário. Recomendo como ponto de partida Lessler, J. T. e Kalsbeek, W. D., Nonsampling Error in Surveys, John Wiley and Sons, Nova Iorque, 1992, Schuman H. e Presser, S., Questions and Answers in Attitude Surveys: Experiments on Question Form, Wording and Context, Academic, Nova Iorque, 1981, e Sudman, S. e Bradburn, N. M., Asking Questions, Jossey-Bass, São Francisco, 1982. Há um rico material sobre o assunto na página na Internet do General Social Survey (www.norc.uchicago.edu), particularmente papers de Tom Smith que versam em sua maioria sobre análise de questionários.

${ }^{2}$ A pesquisa DataUff-CEAP foi feita em todo o Estado do Rio de Janeiro e a pesquisa DataUff-Iuperj apenas no município do Rio de Janeiro. Assim, para efeito desta comparação, foram excluídos os casos da pesquisa DataUff-CEAP que não dizem respeito a este município.
} 
Como se pode perceber, metodologicamente as duas pesquisas são muito semelhantes: as amostras são praticamente idênticas para o município do Rio de Janeiro, e a técnica de levantamento de dados também. Diferenças pequenas podem ser encontradas no tamanho da amostra, que é um pouco maior na pesquisa DataUff-luperj, e no período de realização do trabalho de campo. Enquanto a maior parte das entrevistas tomou 1 mês na segunda pesquisa, na primeira esta duração foi de pouco mais de 3 meses.

As maiores diferenças dizem respeito ao tema das pesquisas, e à distância/proximidade da pesquisa em relação às eleições municipais realizadas em outubro de 2000. O tema da pesquisa DataUff-luperj foi comportamento político e questões correlatas, e a pesquisa foi realizada durante a campanha eleitoral de 2000, coincidindo inclusive com o período de propaganda eleitoral "gratuita" no rádio e na televisão. Por outro lado, a pesquisa DataUff-CEAP ocorreu no início do ano de 2000, distante portanto das eleições, quando sequer as candidaturas estavam oficializadas, e o tema foi relações raciais. Eram poucas as perguntas sobre política nesta pesquisa.

A comparação entre as duas pesquisas é possível porque há perguntas idênticas, ou muito semelhantes, nos dois questionários. Uma delas, importante para realizar inferências acerca do suposto "voto racial", pergunta ao entrevistado se ele já havia votado alguma vez em Benedita da Silva, conhecidamente uma figura de destaque no PT, e que emergiu politicamente com o lema "mulher, negra e favelada". As perguntas foram assim formuladas nas pesquisas:

\section{Pesquisa DataUff-CEAP:}

- O(A) Sr(a) já votou alguma vez em Benedita da Silva?

Pesquisa DataUff-luperj:

- Agora vou dizer o nome de alguns políticos, e gostaria que o(a) Sr(a) me dissesse se já votou alguma vez neles. $\mathrm{O}(\mathrm{A}) \mathrm{Sr}(\mathrm{a})$ já votou alguma vez na Benedita da Silva?

No caso da pesquisa DataUff-CEAP esta pergunta estava localizada na parte final do questionário, no último terço. Ao contrário, na pesquisa DataUff-luperj esta pergunta estava no primeiro terço do questionário, nesta pesquisa a Benedita da Silva era de fato a primeira pessoa da lista de políticos para os quais se perguntou se o entrevistado já havia votado alguma vez.

Como se pode notar, a redação de ambas as perguntas é muito semelhante, e a principal diferença diz respeito realmente à posição das mesmas nos respectivos questionários, e ao contexto no qual as perguntas foram formuladas, no primeiro caso depois de realizadas inúmeras perguntas sobre relações raciais, racismo e temas congêneres, e no segundo caso durante um processo eleitoral, e realizada após a formulação de algumas perguntas sobre política. 
Como pode ser visto no Gráfico 1, o resultado para esta pergunta em cada uma das pesquisas é bastante diferente.

\section{GRÁFICO 1}

Resultados para a pergunta: $O(A)$ Sr(a) já votou alguma vez em Benedita da Silva? Município do Rio de Janeiro (\%)

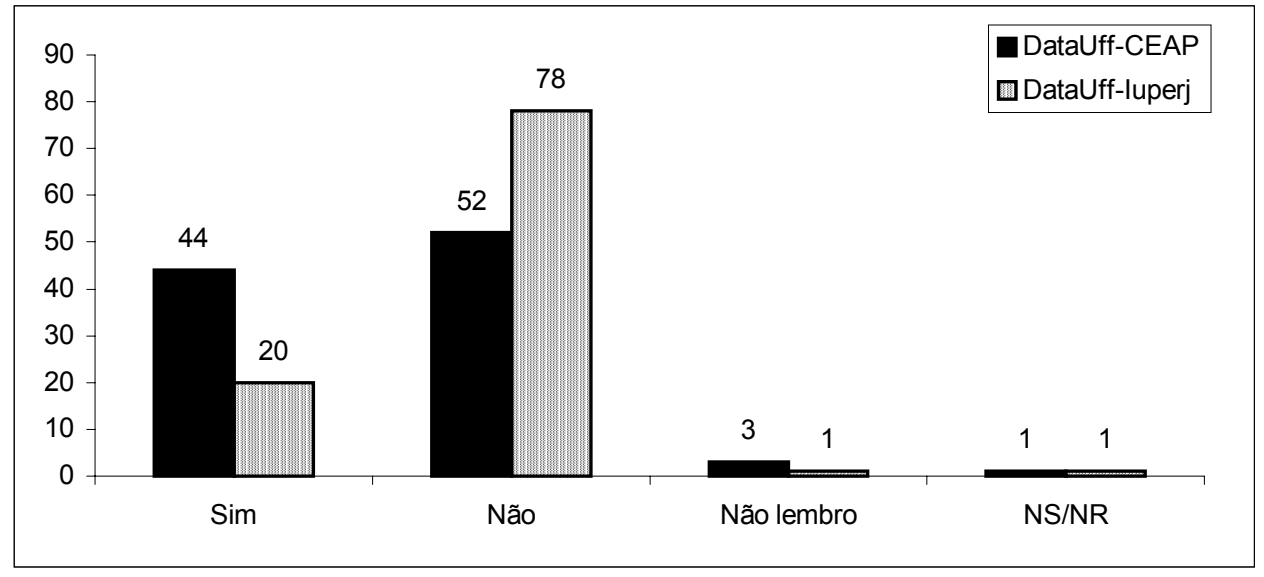

Na pesquisa sobre relações raciais, o percentual de pessoas que afirmam já ter votado em Benedita da Silva é mais de duas vezes maior do que o percentual da mesma resposta quando a pesquisa tem a política como tema. Por outro lado, algo em torno de $50 \%$ dizem nunca ter votado em Benedita quando o contexto de aplicação da pergunta é a pesquisa de relações raciais, enquanto que quase $80 \%$ afirmam nunca ter votado nela na outra pesquisa. A enorme disparidade entre os resultados pode significar que apenas uma das duas pesquisas tem uma medição válida para esta variável, ou nenhuma das duas apresenta esta característica.

Com se tratam de apenas duas pesquisas, uma para cada tipo de pergunta, foram geradas 100 estatísticas (por meio de números aleatórios) para cada uma das pesquisas (portanto, 200 no total) dentro dos limites do erro amostral (mais ou menos 5 pontos percentuais). O resultado deste exercício é apresentado na tabela 1 abaixo.

TABELA 2

Simulação de resultados de pesquisas

\begin{tabular}{|l|c|c|}
\hline Simulação & Média & Desvio padrão \\
\hline DataUff- Ceap & 43,43 & 2,99 \\
\hline DataUff-luperj & 19,68 & 2,93 \\
\hline
\end{tabular}


O teste de diferenças entre médias apresenta uma estatística $F$ muito grande e altamente significante, indicando o que já se esperava: a diferença nos percentuais das respostas não pode ser atribuída à variação causal.

É interessante notar que, quando foi solicitado ao entrevistado para se autoclassificar nas definições de cores do IBGE a diferença entre as pesquisas ficou rigorosamente dentro do erro amostral (Gráfico 2) ${ }^{3}$. Além disso, de acordo com o esperado, uma simulação equivalente à apresentada na Tabela 1 não resulta em uma estatística F significante para este caso.

\section{GRÁFICO 2}

Auto-classificação do entrevistado nas definições de cores do IBGE

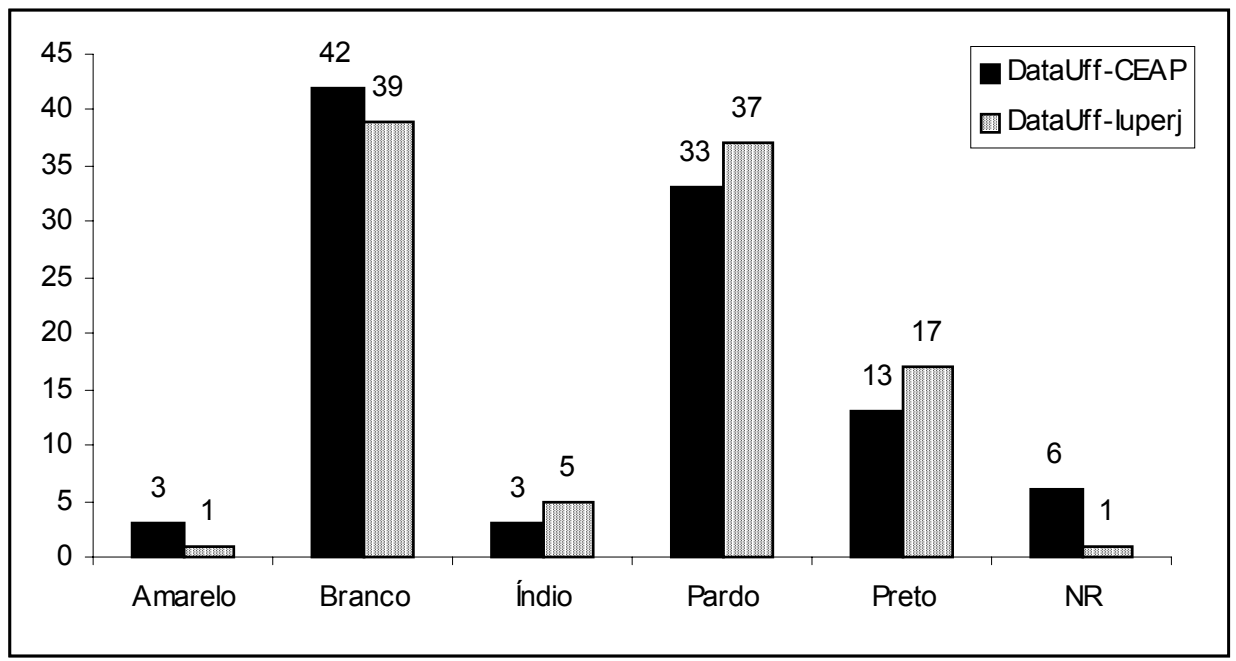

$\mathrm{Na}$ primeira pesquisa a pergunta sobre a auto-classificação da cor no critério IBGE estava no início do questionário, enquanto na segunda pesquisa esta pergunta se encontrava no final. Uma hipótese explicativa para as diferenças entre as duas perguntas, comparando-se as pesquisas, é que na pergunta sobre o voto em Benedita da Silva o entrevistado procurou responder, na pesquisa sobre relações raciais, algo que agradasse ao entrevistado, que fosse socialmente aceitável no contexto daquela pesquisa. Nesta pergunta, diferentemente da que trata da auto-classificação de cor, não há como o entrevistado conferir a validade da resposta, não há como saber se realmente o entrevistado já havia votado em Benedita da Silva. Note-se, todavia, que isto é apenas uma hipótese.

\footnotetext{
${ }^{3}$ Isto acontece também em outras perguntas que constaram dos dois questionários. Alguns exemplos são as perguntas sobre escolaridade, ocupação, religião e preferência partidária.
} 
Os dados comparativos revelam que os menos escolarizados da pesquisa sobre relações raciais, buscaram em maior proporção a resposta afirmativa do que a mesma faixa de escolaridade na outra pesquisa (Gráfico 3).

\section{GRÁFICO 3}

Resultados para a pergunta: O(A) Sr(a) já votou alguma vez em Benedita da Silva? por nível de escolaridade - Município do Rio de Janeiro (\%)

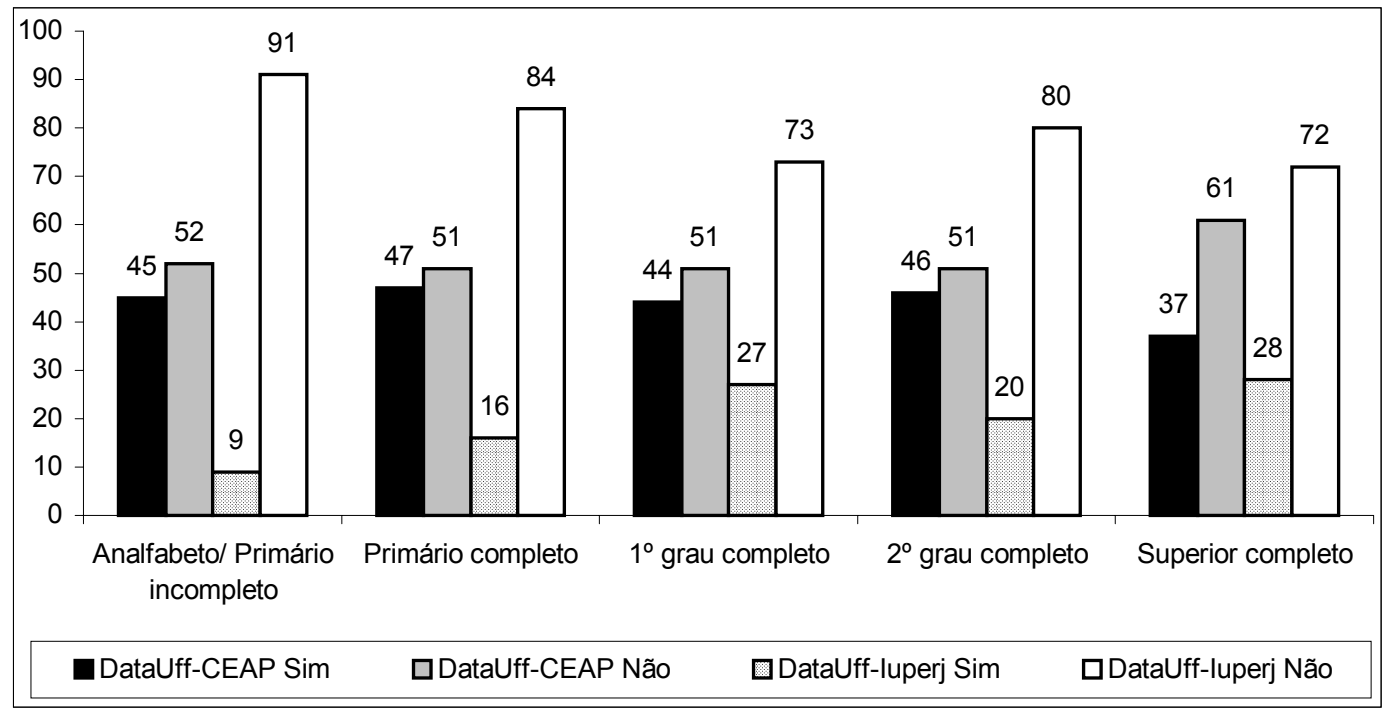

* As somas dos percentuais das respostas $\underline{\operatorname{sim}}$ e não, não totaliza $100 \%$ porque foram excluídas da tabela as respostas não lembro e aqueles que não quiseram responder à pergunta.

Há várias diferenças importantes que merecem ser destacadas. A primeira é que na pesquisa sobre relações raciais as diferenças entre os percentuais de quem responde sim (ou não) por faixa de escolaridade são praticamente inexistentes da escolaridade mais baixa até o $2^{\circ}$ grau completo, e pequena (9\%) entre estas escolaridades e os de grau superior. Na pesquisa que trata de política, pelo contrário, há uma enorme variação: o percentual de eleitores de Benedita da Silva cresce muito com a escolaridade e marca uma diferença de $20 \%$ entre as duas faixas extremas de instrução!

A segunda diferença importante é que na pesquisa sobre relações raciais os de escolaridade superior tendem a votar menos na Benedita do que os de escolaridade mais baixa, é o oposto que ocorre na outra pesquisa, particularmente quando se compara os que têm superior completo com as duas faixas de escolaridade mais baixas.

Por fim, a diferença entre os que responderam sim na faixa de escolaridade mais baixa é de mais $34 \%$ na pesquisa DataUff-CEAP. Esta diferença vai caindo 
com o aumento da escolaridade e atinge o seu mínimo (9\%) junto aos que têm curso superior completo.

Como se sabe, existe correlação entre cor e nível de escolaridade. Na média, os brancos tendem a ter escolaridade mais elevada do que pretos e pardos. Assim, as diferenças apontadas na tabela acima se refletem no voto em Benedita da Silva por cor, como pode ser observado no Gráfico 4.

\section{GRÁFICO 4}

Resultados para a pergunta: O(A) Sr(a) já votou alguma vez em Benedita da Silva? por cor auto-declarada do entrevistado - Município do Rio de Janeiro (\%)

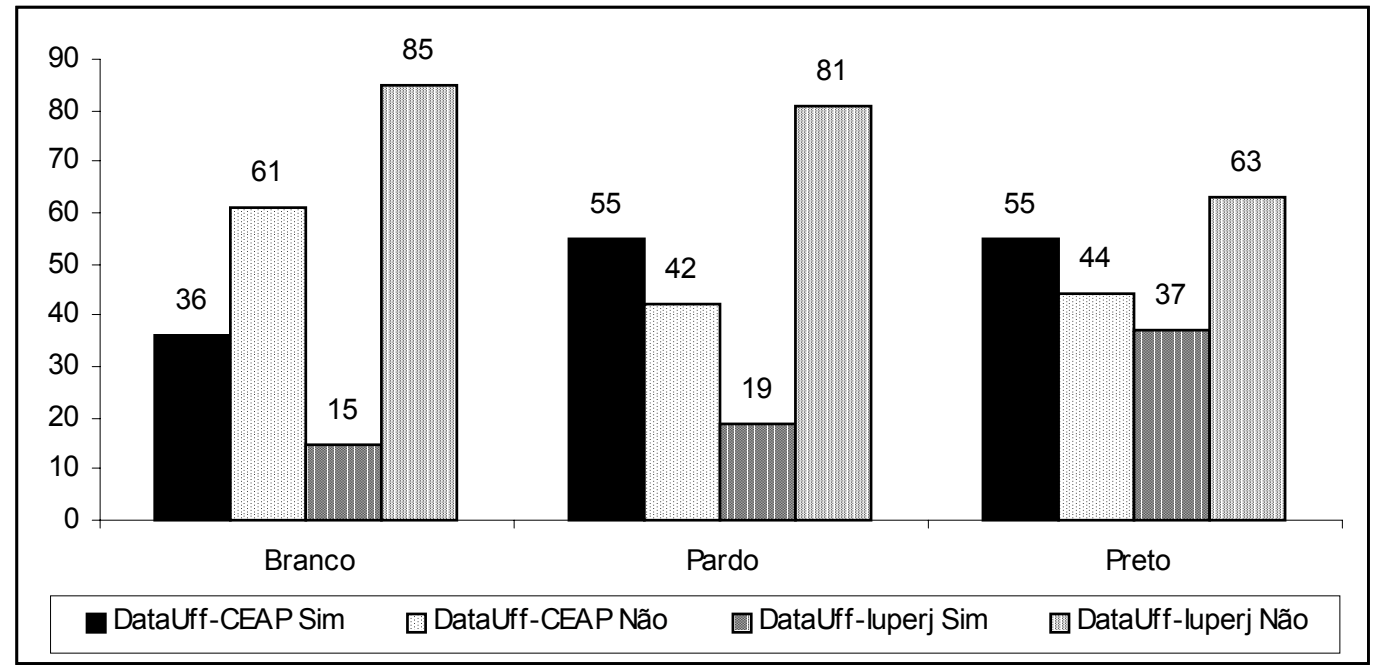

* As categorias amarelo e índio foram eliminadas para efeito deste cruzamento por apresentarem um número muito pequeno de casos em ambas as pesquisas. Mias uma vez, pelas mesmas razões indicadas acima as somas dos percentuais das respostas sim e não, não totaliza $100 \%$

Para as três cores/raças, o percentual daqueles que declaram já ter votado alguma vez em Benedita é bem maior na pesquisa sobre relações raciais do que na pesquisa sobre política. Mais interessante, este percentual é $21 \%$ maior junto aos brancos, $18 \%$ no grupo dos pretos, e $36 \%$ mais elevado junto aos pardos. A rigor, isto significa que dependendo da pesquisa escolhida, obtém-se duas conclusões opostas:

Pesquisa DataUff-CEAP: os pardos tendem a votar de maneira muito semelhante aos pretos. Para as duas cores, 55\% disseram já ter votado em Benedita da Silva, ao passo que esta foi a resposta para apenas $36 \%$ dos brancos.

Pesquisa DataUff-luperj: os pardos tendem a votar de maneira muito semelhante aos brancos. No caso dos pardos, $19 \%$ disseram já ter votado em Benedita da Silva percentual estatisticamente idêntico aos $15 \%$ dos brancos que 
responderam sim a esta questão. Por outro lado, esta foi a resposta para $37 \%$ dos pretos.

O que as duas pesquisas mostram - e há de fato convergência quanto a isto - é que há diferenças importantes entre a proporção de brancos e pretos que votam em Benedita da Silva.

Como afirmado acima, uma das hipóteses explicativas para a grande diferença, entre as pesquisas, dos resultados da pergunta sobre o voto em Benedita da Silva é a da resposta socialmente aceitável. Se isto for verdade, então para esta medição a pesquisa DataUff-luperj seria a mais adequada. Não há como testar de forma adequada esta hipótese. O máximo que se pode fazer é avaliar se na pesquisa DataUff-luperj a posição da pergunta no questionário pode ter influenciado a resposta. Caso haja indícios de que isto não aconteceu, a hipótese da resposta socialmente aceitável em uma pesquisa sobre relações raciais fica fortalecida.

Na pesquisa DataUff-luperj, antes de ser realizada a pergunta sobre se já havia votado antes em Benedita, foram feitas 36 perguntas na seguinte ordem:

- Três perguntas sobre a disponibilidade do entrevistado de ser encontrado em casa;

- Quatro perguntas sobre título de eleitor, local onde vota, se votou na última eleição, se pretendia votar naquela eleição;

- Seis perguntas sobre a situação geral do Brasil, maior problema e situação econômica;

- Duas perguntas sobre intenção de voto para prefeito do Rio de Janeiro;

- Uma pergunta sobre rejeição a candidatos a prefeito do Rio de Janeiro;

- Cinco perguntas de avaliação de desempenho de governantes, sendo 3 destas sobre o presidente;

- 15 perguntas sobre a utilização de diferentes mídias como meio de informação política.

Apenas nas perguntas sobre intenção de voto e rejeição aparecia o nome de Benedita da Silva em um disco, como uma das várias opções de resposta ${ }^{4}$. Isto quer dizer que após a realização de 20 perguntas que não mencionavam o seu nome, foi perguntado ao entrevistado se ele já havia votado alguma vez em Benedita da Silva.

\footnotetext{
${ }^{4}$ Vale registrar que na pesquisa sobre relações raciais, o nome de Benedita da Silva aparecia pela primeira vez justamente na pergunta sobre se já havia votado nela.
} 
Aparentemente a estrutura do questionário não tendia a sub dimensionar a resposta sim a esta pergunta. O inverso pode ter acontecido, porque o nome de Benedita tinha sido mencionado anteriormente, e porque muitos declararam que iriam votar nela nas eleições para prefeito de 2000, então poderia haver uma tendência dos entrevistados a afirmar que já haviam votado em Benedita sem ter de fato feito isto antes. Ainda assim, repito que o mais provável é que a memória sobre o voto em Benedita não tenha sido inflada.

Como afirmado acima, na pesquisa DataUff-luperj havia uma pergunta para mensurar a intenção de voto. Há a possibilidade de que aqueles que afirmaram já ter votado em Benedita, sejam os mesmos que tinham declarado que iriram votar nela na eleição de 2000. A tabela abaixo permite que esta possibilidade seja avaliada.

\section{GRÁFICO 5}

Intenção de voto por voto em Benedita da Silva em eleições anteriores (\%)

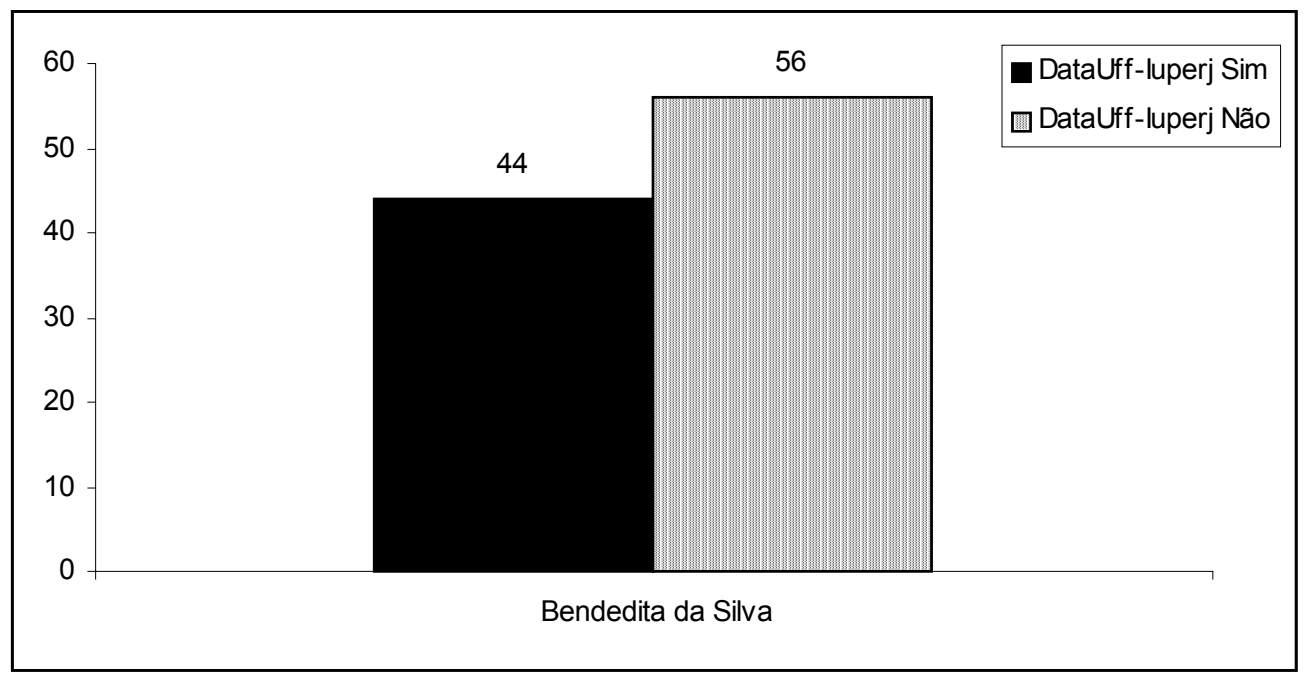

Os dados mostram que há uma divisão ao meio do eleitorado de Benedita da Silva, na eleição de 2000, quando se pergunta se eles já haviam votado anteriormente nela. Isto significa que a pergunta sobre intenção de voto não tendeu a induzir as respostas na pergunta sobre em quem já havia votado.

Para finalizar esta avaliação da validade de uma medição, farei agora a comparação dos resultados das duas pesquisas com as votações que Benedita da Silva teve nas eleições majoritárias na capital. Iniciarei realizando algumas qualificações sobre os dados dos resultados eleitorais: 
1. Benedita da Silva é uma política muito conhecida na cidade do Rio de Janeiro. Ela iniciou sua carreira como vereadora, foi eleita deputada federal, e disputou sua primeira eleição majoritária em 1992, concorrendo ao cargo de prefeito, e sua segunda eleição majoritária foi para uma cadeira no Senado em 1994.

2. Para efeito desta avaliação não considerarei relevante a memória do voto em eleições proporcionais. É razoável supor que há mais dificuldade de se recordar em quem se votou para um cargo legislativo do que para um cargo executivo.

3. Na eleição de 1992 Benedita da Silva teve 32,9\% dos votos válidos no primeiro turno (o que equivale a $21,6 \%$ dos votos de todo o eleitorado uma vez que a abstenção foi de 13,2\%). Esta votação a qualificou para disputar o $2^{\circ}$ turno contra César Maia. No $2^{\circ}$ turno ela teve $48,1 \%$ dos votos válidos, o que equivale a $34,5 \%$ de todo o eleitorado com a abstenção de 15,8\%.

4. Em 1994 Benedita da Silva foi eleita senadora com $44 \%$ dos votos de todo o eleitorado da capital que compareceu às eleições.

5. Quando se considera a memória do voto, as três eleições majoritárias disputadas por Benedita da Silva têm características diferentes:

a. A primeira foi disputada oito anos antes da realização das pesquisas, e a segunda seis anos antes, ou seja, nos dois casos muito tempo se passou entre a eleição e a realização das pesquisas. O resultado esperado é que neste caso o nível de lembrança não seja grande.

b. Há mais chances de se recordar o voto para prefeito do que para senador. Os dados de voto em branco e voto nulo mostram que o eleitor valoriza mais a eleição para o prefeito de sua cidade do que para o Senado. O cargo de Senador é visto pelo eleitor como algo mais distante, mais intangível.

c. Há mais chances de se recordar do voto no $1^{\circ}$ do que do $2^{\circ}$ turno. $\mathrm{Na}$ eleição em dois turnos o eleitor escolhe o seu candidato preferido no primeiro turno. Em geral no segundo turno a lógica de escolha é diferente: ou se repete o voto no candidato do $1^{\circ}$ turno, um percentual muito grande de eleitores faz isto quando o seu candidato passa para a $2^{\mathrm{a}}$ rodada eleitoral, ou se escolhe o menos pior quando seu candidato preferido não vai para o $2^{\circ}$ turno.

6. Como afirmado acima, quando um candidato passa para $\circ 2^{\circ}$ turno 0 eleitor tende a repetir o voto dado no $1^{\circ}$ turno. A proporção daqueles que mudam de voto, atestada pelas pesquisas de opinião, é muito pequena, da ordem de $5 \%$. Além disso, no caso de Benedita da Silva, é razoável supor que muitos dos que votaram nela em 1992 para prefeita, votaram novamente nela para senadora em 1994. Há razões para se fazer esta suposição: 
a. As duas eleições foram próximas, separadas apenas por dois anos, período este no qual Benedita da Silva permaneceu em evidência na mídia, mantendo na memória o voto de seu eleitor de 1992.

b. Os eleitores simpatizantes do PT tendem a votar nos candidatos do PT.

c. A derrota de Benedita para César Maia para a prefeitura foi de virada e apertada, deixando frustrados seus eleitores. A eleição de 1994 seria uma maneira de dar a vitória que Benedita não teve dois anos antes.

Realizadas estas qualificações, apresento na tabela abaixo o percentual dos que afirmaram em cada uma das pesquisas já ter votado em Benedita, e os seus votos nas eleições majoritárias que ela disputou, como proporção de todo o eleitorado da capital, ou seja, considerando-se as abstenções.

\section{TABELA 3}

Voto em Benedita da Silva em eleições majoritárias e memória do voto (\%)

\begin{tabular}{|c|c|c|c|c|}
\hline \multicolumn{3}{|c|}{ Eleições majoritárias } & \multicolumn{2}{c|}{ Já votou em Benedita } \\
\hline $1992(1)$ & $1992(2)$ & 1994 & DataUff-CEAP & DataUff-Iuperj \\
\hline 21,6 & 34,5 & $44^{*}$ & 44 & 20 \\
\hline
\end{tabular}

* O percentual foi calculado sobre o total dos eleitores que compareceram às urnas no município do Rio de Janeiro. Caso tivesse sido sobre todo o eleitorado, ou seja, considerando-se abstenções, este percentual seria bem menor.

Há uma diferença fundamental entre as duas pesquisas. Na pesquisa sobre relações raciais, o percentual daqueles que afirmam já ter votado em Benedita é maior do que os percentuais de voto da Benedita em cada eleição separadamente. No caso da outra pesquisa ocorre exatamente o oposto, esta proporção é menor do que suas votações. A pesquisa DataUff-CEAP apresentaria o resultado mais acurado caso a cada eleição o conjunto de eleitores de Benedita fosse totalmente diferente, ou ao menos muito diferente, da eleição anterior, o que significa negar a qualificação número 6 que assume que o eleitor tende a repetir o voto. Além disso, seria necessário também desconsiderar - o que é impossível - os efeitos das mudanças demográficas: falecimento de eleitores, eleitores que deixam de votar por causa da idade, e eleitores que passaram a votar depois de 1994, quando Benedita disputou sua última eleição majoritária.

Assim, os indícios apontam que a pesquisa DataUff-luperj, para esta medição em particular, é mais acurada que a pesquisa DataUff. CEAP. Isto significa que as evidências aqui apresentadas tendem a sustentar a hipótese de que os entrevistados na pesquisa sobre relações raciais buscaram a resposta socialmente aceitável. No final do questionário, que tratava em inúmeras perguntas de preconceito racial, seria "politicamente correto" responder que já havia sido eleitor de Benedita da Silva. 


\section{Conclusões}

A análise da medição realizada por duas perguntas muito semelhantes revelam alguns pontos que merecem destaque.

\section{1 - Pequenos detalhes importam}

A elaboração de um questionário de pesquisa pode parecer, à primeira vista, uma tarefa simples e trivial. Contudo, o exemplo deste artigo mostra que os efeitos do posicionamento de uma pergunta no questionário sobre os resultados da pesquisa podem ser muito grandes, e até mesmo invalidar os resultados de uma pesquisa. Assim, o que é detalhe se torna extremamente relevante, exigindo que os questionários de pesquisa sejam cuidadosamente elaborados e pré-testados. Uma alternativa a isto é a utilização de casos como o apresentado aqui, e a realização de experimentos com perguntas.

\section{2 - 0 efeito do contexto da pesquisa}

Toda pesquisa tende a apresentar em seus resultados os efeitos do contexto. No caso do voto em Benedita da Silva, a pesquisa sobre relações raciais foi o contexto que levou os entrevistados a se lembrarem mais deste voto do que em uma pesquisa sobre política. Afinal, pegaria mal passar uma pesquisa inteira dizendo que não é racista, e ao final da entrevista dizer que nunca havia votado em Benedita da Silva. Em cada pesquisa este contexto é diferente, e ele pode não ser apenas o tema da pesquisa, mas também sub-temas de perguntas em um questionário. O contexto pode ser também as condições externas à pesquisa, situações de comoção nacional ou congêneres podem vir a influenciar nos resultados de uma pesquisa, dependendo, é claro, do tema pesquisado. 